leading to less cell breakdown and more effective erythropoiesis. If so, an increase in normal erythropoiesis might lead to a greater mobilization of available iron, and this, together with the fetal demands, might lead to a negative iron balance and a state of iron deficiency in the absence of iron supplements.

Early iron deficiency may be difficult to diagnose. The value of measuring serum iron levels is limited when anaemia is minimal or iron deficiency is incipient. The T.I.B.C. usually increases with depletion of iron stores, but it also normally increases in pregnancy and, therefore, a rising level may be difficult to interpret. Absent iron stores are generally accepted as a feature of iron deficiency. The absence of iron stores in itself may not be of great importance and an increased ingestion or absorption of food iron may be enough to satisfy iron requirements during a period of greater demand, ${ }^{10}$ such as pregnancy. The number of sideroblasts in a bone marrow film is probably a more accurate index and sideroblast counts of less than $10 \%$ indicate iron deficient erythropoiesis. Of the 22 patients in whom bone marrow examinations were done 21 showed this feature. This finding apparently contradicts those of Schuman et al. ${ }^{9}$ but in most of their patients bone marrow examination was carried out before the 28th week of pregnancy and they make the point that their limited data on bone marrow haemosiderin after the 32nd week also suggested a diminution of iron stores during pregnancy. Iron absorption is not increased in patients with $\beta$-thalassaemia trait, ${ }^{11}$ and Pakes et al. ${ }^{12}$ emphasized that these patients possess the same increased requirements for iron during pregnancy as do other women without this defect.

The serum folate and $\mathrm{B}_{12}$ levels were all normal except in one patient, who had a low serum folate and showed mild megalo- blastic change on bone marrow examination. These findings imply that these patients tend to remain in positive balance for vitamin $B_{12}$ and folic acid, but they do not exclude increased demands.

Hence, iron deficiency seems to be common in pregnant women with $\beta$-thalassaemia trait, and these patients should be given oral iron and physiological doses of folic acid throughout pregnancy, as are other women without this defect.

We thank the consultant obstetricians, North Middlesex Hospital, for help in studying these patients. We thank Miss C. Hollywell and Miss S. Fairhurst for expert technical help.

\footnotetext{
References

${ }^{1}$ Fleming, A. F., and Lynch, W., Fournal of Obstetrics and Gynaecology of the British Commonwealth, 1969, 76, 451.

${ }^{2}$ Wasi, P., Disthasongchan, P., and Na-Nakorn, S., Fournal of Laboratory and Clinical Medicine, 1968, 71, 85.

3 Dacie, J. V., and Lewis, S. M., Practical Haematology, 4th edn. London, Churchill, 1968.

4 Marengo-Lowe, A. J., Fournal of Clinical Pathology, 1965, 18, 790.

5 Singer, K., Chernoff, A. I., and Singer, L., Blood, 1951, 6, 413.

${ }^{6}$ England, J. M., and Fraser, P. M., Lancet, 1973, 1, 449.

7 Goldberg, M. A., and Schwartz, S. O., Blood, 1954, 9, 648.

${ }^{8}$ Hegde, U. M., and Khunda, S., Fournal of Obstetrics and Gynaecology of the British Commonwealth, 1974, 81, 136.

${ }^{9}$ Schuman, J. E., et al., British Fournal of Haematology, 1973, 25, 249.

10 Isager, H., Scandinavian fournal of Haematology, 1974, no. 21 (Suppl.), p. 9 .

${ }^{11}$ Shahid, M. J., and Haydar, N. A., British Fournal of Haematology, 1967, 13, 713.

${ }^{12}$ Pakes, J. B., Copperberg, A. A., and Gelfand, M. M., American fournal of Obstetrics and Gynecology, 1970, 108, 1217.
}

\title{
Evaluation of Creatinine Phosphokinase in Screening Patients for Malignant Hyperpyrexia
}

\author{
F. RICHARD ELLIS, I. M. C. CLARKE， MARGARET MODGILL， S. CURRIE, \\ D. G. F. HARRIMAN
}

British Medical fournal, 1975, 3, 511-513

\section{Summary}

Evidence is presented that serum creatinine phosphokinase (CPK) activity is of no direct value in screening patients for susceptibility to malignant hyperpyrexia and does not correlate with halothane-induced muscle contracture or the presence of myopathy. Widely differing CPK values were found at different times in the same people. In most "malignant hyperpyrexia" families the susceptible patients had either normal or inconsistently raised CPK values.

\footnotetext{
Malignant Hyperpyrexia Investigation Unit, University of Leeds, Leeds LS2 9LN

F. RICHARD ELLIS, PH.D., F.F.A. R.C.S., Senior Lecturer in Anaesthesia I. M. C. CLARKE, M.B., F.F.A. R.C.s., Research Fellow

MARGARET MODGILL, M.B., F.F.A. R.C.S., Senior Registrar

S. CURRIE, M.D., M.R.C.P., Consultant Neurologist

D. G. F. HARRIMAN, M.D., F.R.C.S., Senior Lecturer in Neuropathology
}

\section{Introduction}

The syndrome of malignant hyperpyrexia under anaesthesia, characterized by a rapid rise of body temperature (greater than $2{ }^{\circ} \mathrm{C}$ per hour), acidosis, hyperkalaemia, and usually muscle rigidity, carries a $60-70 \%$ mortality. ${ }^{1}$ The condition is inherited as a Mendelian dominant and so screening all members of an indexed family before anaesthesia is mandatory.

The association of myopathy with malignant hyperpyrexia ${ }^{2}{ }^{3}$ led to the suggestion that serum creatinine phosphokinase (CPK) levels may be consistently raised in susceptible patients. $\mathrm{CPK}$ is now commonly used to indicate susceptibility to malignant hyperpyrexia in relatives and yet some susceptible patients have normal CPK levels. ${ }^{4}$

Muscle from susceptible patients was found to develop contracture in vitro when exposed to certain known trigger agents including halothane. ${ }^{5}$ The same muscle tissue when investigated neuropathologically was also found to have structural abnormalities consistent with myopathy. ${ }^{3}$ The discovery of these abnormalities enabled us to offer a screening test for malignant hyperpyrexia using muscle biopsy. When a family is investigated the indexed patient is studied first because there are other unrelated causes of hyperpyrexia under anaesthesia which can mimic malignant hyperpyrexia. So far $10 \%$ of the indexed patients referred to us for investigation have been found to have normal muscle, and other causes of the hyperpyrexia have been 
sought. When a diagnosis of malignant hyperpyrexia has been confirmed with the laboratory tests other members of the family are offered the investigation.

Our aim was to assess the relevance of CPK levels in patients shown to be susceptible to malignant hyperpyrexia using the muscle contracture screening test and structural abnormalities of muscle as identifiers. We report here the results of the first 52 biopsies performed on patients referred to us.

\section{Methods}

Fifty-two patients with either a personal history of malignant hyperpyrexia during anaesthesia or relatives who had malignant hyperpyrexia were investigated. Motor point muscle biopsy of, usually, the left vastus internus muscle was performed under a form of general anaesthesia. We used general anaesthesia, using drugs not then implicated in the aetiology of malignant hyperpyrexia, because local infiltration anaesthesia hinders the identification of the motor point by electrical stimulation and greatly alters the reactivity of the muscle for in-vitro pharmacological screening. Thiopentone, fentanyl citrate, and nitrous oxide were administered after oral premedication with diazepam and body temperatures were recorded continuously at six different sites-namely, rectum, tympanic membrane, muscle, and three skin sites. The procedure lasted about 90 minutes, during which two specimens were taken for in-vitro pharmacological screening and 12 specimens were taken for neuropathological study including electron and light microscopy, neurohistochemistry, and tissue culture. All specimens were taken across the motor point and so motor nerve and endplate were included in all the investigations.

Each patient was venepunctured the day before investigation, at induction of anaesthesia, and the day after investigation. Blood was taken so that serum electrolytes and serum enzymes including CPK, aldolase, lactic dehydrogenase, alkaline phosphatases, and the transaminases could be estimated. Blood samples for CPK were taken without venous occlusion in fasting patients who had not undertaken strenuous exercise or had intramuscular injections within 48 hours. The CPK was determined using the standard Boeringer CPK kit.

\section{Results}

Normal muscle when exposed in vitro to inhalational anaesthetic vapours in roughly clinical concentrations develops a reduction in tension. Any increase in tension is interpreted as positive evidence of susceptibility to malignant hyperpyrexia. As there seems to be a definite variation in the degree of increase in tension with halothane, however, the results were expressed nonparametrically: $0=$ no increase in tension with up to $2 \%$ halothane (normal muscle); $1=$ less than $100 \%$ increase in tension with $0.5 \% \mathrm{v} / \mathrm{v}$ halothane; and $2=$ greater than $100 \%$ increase in tension with $0.5 \% \mathrm{v} / \mathrm{v}$ halothane.

To allow for a comparison with the pharmacological studies the degree of morphological abnormality in the pathological studies was expressed similarly: $0=$ normal muscle; $1=$ minimal but definite changes consistent with myopathy; and $2=$ severe myopathic changes. This classification was based on the criteria shown in table I.

Normal muscle included a range of morphological variation-in fibre size, numerical density of mitochondria, intensity of glycogen staining, etc. Single examples of any of the pathological changes shown in table I were ignored. Scoring was assessed on the incidence or abnormality per fascicle. Scores for different abnormalities were not added together-for example, a specimen showing moth-eaten fibres rated 1 and small angulated fibres rated 1 was assessed as 1 overall.

TABLE I-Number of Structural Abnormalities per Fascicle

\begin{tabular}{l|c|c}
\hline & $\begin{array}{c}\text { Grade 1 } \\
\text { Myopathy }\end{array}$ & $\begin{array}{c}\text { Grade 2 } \\
\text { Myopathy }\end{array}$ \\
\hline Internal nuclei & $2-9 \%$ & $>9 \%$ \\
"Moth-eaten" fibres & $<2$ & $22 \%$ \\
Core-targetoid fibres & $<25 \%$ & $25 \%$ \\
Type 1 fibre atrophy & $<25 \%$ & $25 \%$ \\
Type 2 fibre atrophy & $<2$ & $\geqslant 2$ \\
"Sibre splitting & $<2$ & $\geqslant 2$ \\
Tubuttar aggregates & $<2$ & $\geqslant 2$ \\
Necrosis/regeneration & $<2$ & 2 \\
Small angulated fibres & & \\
\hline
\end{tabular}

TABLE II-Correlation between Pharmacological and Pathological Results. Results are Numbers of Patients

\begin{tabular}{|c|c|c|c|}
\hline \multirow{2}{*}{ Myopathy } & \multicolumn{3}{|c|}{ Muscle Contracture } \\
\hline & 0 & 1 & 2 \\
\hline $\begin{array}{l}0 \\
1 \\
2\end{array}$ & $\begin{array}{r}20 \\
0 \\
0\end{array}$ & $\begin{array}{l}\mathbf{4} \\
\mathbf{4} \\
\mathbf{7}\end{array}$ & $\begin{array}{r}2 \\
1 \\
14\end{array}$ \\
\hline
\end{tabular}

Table II shows the correlation between the pharmacological and pathological results, which was highly significant $(P<0.001)$. The absence of a perfect correlation was due mainly to the seven patients who had grade 2 myopathy with only grade 1 halothane-induced contracture, and there were two patients with grade 2 and four patients with grade 1 muscle contracture with normal muscle morphology.

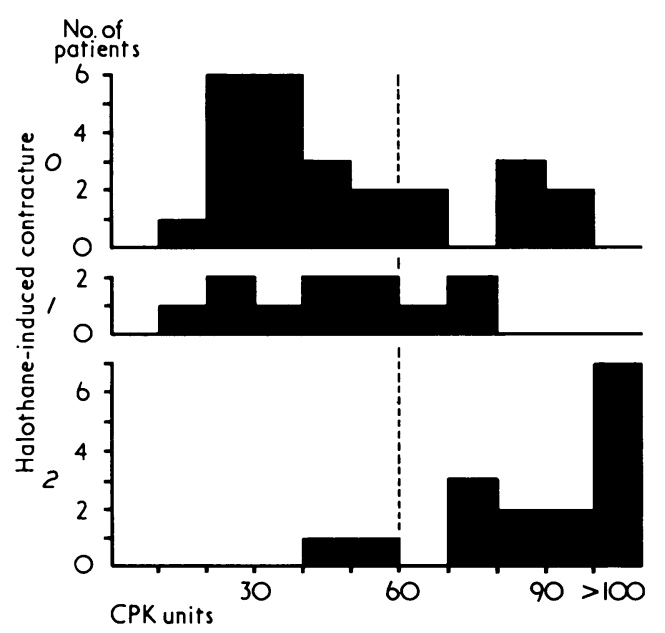

FIG. 1-Frequency histogram of degree of halothaneinduced muscle contracture against ranked CPK.

Fig. 1 shows the ranked CPK results grouped according to the degree of in-vitro contracture. In groups 0 and 1 the CPK results were similar in distribution; most patients fell into the normal CPK range for our laboratory of less than $60 \mathrm{U} / \mathrm{l}$ and the group means were within the normal range (table III). Group 2 had a different distribution and the group mean CPK $(227 \mathrm{U} / \mathrm{l})$ was significantly raised. The important clinical finding, however, was that some normal patients had raised CPK levels (false positive if the CPK is used to screen for malignant hyperpyrexia), and, even more important clinically, 10 patients with an abnormal in-vitro reaction to halothane were within normal limits for CPK (false negatives).

Fig. 2 shows the ranked CPK results grouped according to the degree of morphological muscle abnormality. The pattern was substantially similar to that shown in fig. 1 for the halothane-induced contracture results. Again the group 2 had a significantly raised mean $\mathrm{CPK}$ of $175 \mathrm{U} / 1$ (table III) and there were false-positive and falsenegative CPK results in all groups.

The variability of the CPK between different families is shown in table IV. Three families were investigated in whom all the members susceptible to malignant hyperpyrexia had raised CPK levels; in two of these families the CPK levels were very high. Two families contained members susceptible to malignant hyperpyrexia whose CPK levels were consistently within the normal range, and in two families the CPK results of susceptible patients were inconsistently raised.

TABLE III-Mean CPK Levels according to Pharmacological and Pathologica Gradings

\begin{tabular}{|c|c|c|c|c|c|c|}
\hline & \multicolumn{3}{|c|}{ Halothane Contracture } & \multicolumn{3}{|c|}{ Muscle Pathology } \\
\hline & 0 & 1 & 2 & 0 & 1 & 2 \\
\hline $\begin{array}{l}\text { Mean (t S.D. }) \\
\text { CPK (U/I) }\end{array}$ & $48 \pm 5$ & $46 \pm 6$ & $227 \pm 61^{*}$ & $41 \pm 4$ & $55 \pm 9$ & $175 \pm 48^{*}$ \\
\hline
\end{tabular}

*Significant deviation from normal $(P<0.02)$. 
TABLE v-Variations in CPK Levels within and between Patients

\begin{tabular}{|c|c|c|c|c|c|c|c|}
\hline \multirow{2}{*}{$\begin{array}{c}\begin{array}{c}\text { Patient } \\
\text { Case No. }\end{array} \\
1 \\
2 \\
3 \\
4\end{array}$} & \multicolumn{4}{|c|}{ CPK Levels on Different Occasions } & $\underset{(\mathbf{U} / \mathbf{l})}{\operatorname{Mean} \mathrm{CPK}}$ & \multirow{2}{*}{$\begin{array}{c}\begin{array}{c}\text { Halothane } \\
\text { Contracture } \\
\text { Grade }\end{array} \\
2 \\
0 \\
1 \\
0\end{array}$} & \multirow{2}{*}{$\begin{array}{c}\text { Myopathy } \\
\text { Grade }\end{array}$} \\
\hline & $\begin{array}{l}31 \\
70 \\
66 \\
88\end{array}$ & $\begin{array}{l}44 \\
30 \\
27 \\
46\end{array}$ & $\begin{array}{r}49 \\
29 \\
139 \\
133\end{array}$ & $\begin{array}{l}64 \\
35\end{array}$ & $\begin{array}{l}47 \\
41 \\
77 \\
85\end{array}$ & & \\
\hline
\end{tabular}

The variability of CPK estimations in an individual patient even when blood was taken under optimal conditions was unpredictably great. The first two patients in table $\mathrm{V}$ were brothers, one of whom was highly susceptible and the other non-susceptible to malignant hyperpyrexia. Out of four CPK estimations each brother had one raised value and three normal values and their mean CPK values were not significantly different. Cases 3 and 4 showed similarly unreliable CPK values. The patient in case 3 , though susceptible to malignant hyperpyrexia, had one normal CPK value and a mean value less than that of the patient in case 4 , who was found to be normal.

TABLE IV-Variations in CPK Levels and Susceptibility to Malignant Hyperpyrexia between Families

\begin{tabular}{|c|c|c|c|}
\hline Family & $\begin{array}{c}\text { No. of Members } \\
\text { Biopsied }\end{array}$ & $\begin{array}{l}\text { No. found } \\
\text { Susceptible }\end{array}$ & $\begin{array}{c}\text { Mean CPK of } \\
\text { Susceptibles } \\
(\mathbb{U} / 1)\end{array}$ \\
\hline \multicolumn{4}{|c|}{ Families with Consistently Raised CPK } \\
\hline $\begin{array}{l}\text { A } \\
\text { B } \\
\text { C }\end{array}$ & $\begin{array}{l}3 \\
6 \\
3\end{array}$ & $\begin{array}{l}2 \\
4 \\
2\end{array}$ & $\begin{array}{r}750 \\
320 \\
84\end{array}$ \\
\hline \multicolumn{4}{|c|}{ Families with Inconsistently Raised CPK } \\
\hline$\stackrel{\mathrm{D}}{\mathrm{E}}$ & $\begin{array}{l}7 \\
5\end{array}$ & $\begin{array}{l}3 \\
4\end{array}$ & $\begin{array}{l}51 \\
67\end{array}$ \\
\hline \multicolumn{4}{|c|}{ Families with Consistently Normal CPK } \\
\hline F & $\begin{array}{l}5 \\
3\end{array}$ & $\begin{array}{l}2 \\
2\end{array}$ & $\begin{array}{l}25 \\
44\end{array}$ \\
\hline
\end{tabular}

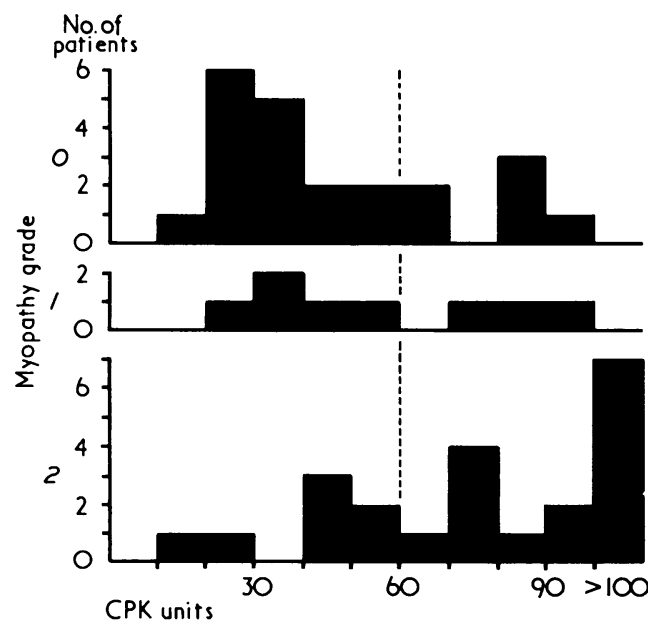

FIG. 2-Frequency histogram of degree of myopathy against ranked CPK.

\section{Discussion}

Anaesthesia for patients susceptible to malignant hyperpyrexia can be provided using non-standard methods. If, however, patients are not screened those who are normal will be unidentified and will either suffer unnecessarily the increased risk of an anaesthetic designed to avoid all the known trigger drugs or have to have conservative rather than surgical treatment to avoid a general anaesthetic. All future generations will suffer similarly. Thus, the justification for screening all patients from known families is, firstly, to identify those who require special anaesthesia; secondly, to know which future generations may be at risk; and, thirdly, to remove the stigma of malignant hyperpyrexia from those found to be normal.

Measuring CPK activity cannot be considered to be an adequate screening test for susceptibility to malignant hyperpyrexia. Nevertheless, in a few families in which people susceptible to malignant hyperpyrexia have high CPK levels CPK may be of some value as an initial screen, and it has helped us to decide whom to investigate first by muscle biopsy.

The high CPK levels were generally found in patients with the most severe halothane contracture and morphological abnormality, and it is pleasing to find that these two laboratory indices of muscle abnormality have such a high degree of correlation.

When evaluating the laboratory results it became apparent that there were varying degrees of abnormality on both the pharmacological and pathological investigations. Perhaps the variation is a continuum from the mild to severe. The grouped CPK results confirm that the less severely affected patients have CPK levels largely within the normal range. It is tempting to suggest that the degree of muscle abnormality indicates the severity of the clinical course of malignant hyperpyrexia, but as many of the patients investigated have never had malignant hyperpyrexia themselves this hypothesis awaits further evaluation. There is no indication that death occurs more commonly in families with high CPK levels, but susceptible relatives of patients who have died from malignant hyperpyrexia do seem to have more severe pharmacological and morphological muscle abnormalities.

In conclusion, we believe that estimation of CPK cannot be used as a test for predicting susceptibility to malignant hyperpyrexia unless the patient belongs to a family in which high CPK levels have been shown to correlate with susceptibility to malignant hyperpyrexia.

F.R.E. wishes to acknowledge the financial assistance provided by the Association of Anaesthetists of Great Britain and Ireland, I.C.I. (Pharmaceuticals) Ltd., and Cyprane Ltd. I.M.C.C., D.G.F.H., and F.R.E. are in receipt of grants from the Leeds General Infirmary Endowment Fund. D.G.F.H. and F.R.E. wish to acknowledge financial support from the West Riding Medical Trust and D.G.F.H. from the Medical Research Council. We would like to thank the department of chemical pathology, Leeds General Infirmary, for the CPK results.

\section{References}

${ }^{1}$ Britt, B. A., and Kalow, W., Canadian Anaethetists' Society fournal, 1970, $17,293$.

2 Issacs, H., and Barlow, M. B., British Medical fournal, 1970, 1, 275.

3 Harriman, D. G. F., Sumner, D. W., and Ellis, F. R., Quarterly fournal of Medicine, 1973, 42, 639.

${ }^{4}$ Ellis, F. R., Anaethesia, 1973, 28, 245.

${ }^{5}$ Ellis, F. R., et al., British fournal of Anaethesia, 1971, 43, 721. 